\title{
Competition dynamics in Nigerian aviation industry: a game theoretic approach
}

\author{
Olatunji Abdul Shobande ${ }^{1 *}$ and Mobolaji Daniel Akinbomi
}

\begin{abstract}
Background: This paper develops a game theoretic model that analyses the dynamics of competition among the leading domestic aviation firms in the Nigerian aviation industry. It probes the abilities of the prisoner dilemma to describe the subjective behaviour of the firms, which provide a yardstick for assessing the optimal competitive strategies available to the firm to survive the business environment.
\end{abstract}

Results: The solution of the game provides different optimal competitive strategies for the firms. While findings show that Aero Contractors placed more weight on flight pricing to survive in the industry, Arik Air needed to retain nonpricing competitive strategy to remain the leading domestic aviation firm in Nigeria.

Conclusion: Based on our findings, we conclude that if both firms stick to the optimal strategy, they would both share the market.

Keywords: Firm strategy, Game theory, Duality, Aviation industry

JEL Classification: L2, L11, C69, C70, C71

\section{Introduction}

The paper focuses on the Nigerian aviation industry, which has continued to experience historic changes, growth, and development. We provide evidence by applying the prisoner dilemma theoretic intuition to experiment with the competitive dynamics of the industry. We work with two leading aviation firms that serve as the main drivers of the Nigerian aviation business with the aim of investigating the various economic strategy employed by the firms to navigate the dynamics of aviation business environment in which they operate.

In recent pasts, there have been remarkable transformations in the airlines industry, which have influenced economic efficiency and the high degree of competition noticed among operators. Interestingly, the deregulation and liberalisation of the sector also contributed in motivating new entry of firms into the sector [1]. However,

\footnotetext{
*Correspondence: o.shobande.19@abdn.ac.uk

${ }^{1}$ Business School, University of Aberdeen, Block C, Room F02, Edward

Wright Annexe, Aberdeen AB23 3RX, UK

Full list of author information is available at the end of the article
}

the effects of less regulation provided passengers with different choices in terms of price service options for different routes. According to available analysis, the Nigerian airline industry is still far from hitting the peak of competition milestone as may be expected, despite the remarkable transition experienced [2]. One major challenge often cited has been the inability to reconcile the existing pricing strategies and customer protection [3]. This remains a huge concern and demands regulatory response/intervention to avoid over exploitation of passengers while reassuring that prices are to some degree beneficial to the services.

In explaining the analysis of existing market structure and providing yardstick for economic strategy and managerial decision of firm, in order to provide service delivery to passengers without monopolistic tendency of the firms, this study examines the effect of price charges on passengers' patronage among two leading airline operators in the Nigerian aviation industry. Specifically, the objectives are to: (1) determine the best strategy to adopt by Arik Air and Aero Contractors in surmounting identified challenges. The strategy can either be a price or an 
output, since firms compete on price and non-price variables (2) determine mathematically, the payoffs from the best strategy that will be chosen by each firm.

The paper also aims at providing three important contributions to both theoretical and empirical understanding of the nature and structure of competition in the aviation market. First, the paper develops a game theory based on linear programming in the analysis of the existing competition and market structure in the Nigerian aviation industry. The approach provides the yardstick for evaluating the economic strategy adopted between the firms to survive their business environment. Second, the outcome of the experiment provides various managerial strategies that can be adopted by management of these firms to improve their service delivery and maximise passenger patronage. Third, the innovative part of the paper is the ability to reconcile the growing misconception that regulation often result to inefficiency and high cost of doing business in Nigeria. The result shows that the existing system seems rigid and encourages exploitation of passengers as the operators rely on pricing strategy as a measure to motivate customer. This is also blamed for the poor service delivery experienced in the industry. Thus, the need for proactive economic policy that will reassure customer protection and efficient service delivery cannot be ignored in the context of the Nigerian aviation industry.

\section{Background and hypothesis development Background}

Historically, competition in the Nigerian aviation industry can be traced to the pre- and post-independence eras. The pre-independence development in the industry was occasioned by riotous feud between the British colonial administration and the people of Kano city in 1925, while the post-independence development saw that the Federal Government buy out other shareholders of Nigerian Airways thereby making the airline wholly owned by the Nigerian government. At this time, the airline had a monopoly for providing domestic services in Nigeria [2]. It was also the national flag carrier for international services along the West African coast, Europe and the USA. The need for further transformation of the country's air transport services led to the eventual deregulation of the industry by the government $[4,5]$. This action signalled unrestricted competition among the operators leading to the proliferation of small airline companies in Nigeria.

In pursuance of the deregulation policy of the aviation industry, about 25 private airline operators were licensed in the early 1990s to contribute to the development of the industry. The emergence of private airline operators successfully broke the state monopoly (i.e. the Nigerian Airways) as they continue to run commercial air operations on most domestic trunk routes. The open skies policy delivered yet another liberalisation policy adopted to increase competition and growth of the industry in Nigeria. The open skies policy had as its core the unrestricted access of airlines to different destinations. Even though the domestic airlines in Nigeria are plagued by capacity challenge and poor service delivery, we argued that strategic approach to overcoming these identified issues should be taken if the domestic airlines will survive the harsh operating environment. Thus, this study employs the technique of strategic decision in the context of game theory to obtain the optimal strategy for the survival of the Nigerian aviation firms, namely Arik Air and Aero Contractors. In view of this, the problem addressed in the study is, how will competitors determine the optimal strategy to employ in order to remain competitive and survive the turbulent-cum-harsh operating/business environment? This remains unsolved in the aviation literature within the Nigerian context. It is this lacuna that this study seeks to fill.

\section{Hypothesis development}

In light of the above, two hypotheses were tested for this study:

Hypothesis 1 Does pricing behaviour determine passenger patronage among the leading airline firms in Nigeria?

Hypothesis 2 What is the optimal competitive strategy available to each firm to remain competitive in the aviation business environment?

For each hypothesis to be valid, the effect of pricing behaviour must reflect the gain of each firm over its competitor. Hence, to test the degree of competition among the leading aviation firms in Nigeria, we must compare the price behaviour and passengers' patronage with its existing output. On the other hand, we tested the ability of the firms to cope within their business environment by checking the optimal strategy it can adopt to improve its market share through efficient price service options.

The rest of the paper is organised as follows: the next section presents the review of related literature and methodology, followed by the last section, which concludes the paper with some policy implications of our findings.

\section{Review of related literature}

In this section, we discuss the various theoretical underpinning and empirical arguments surrounding pricing behaviour and drivers of competition in the aviation industry. 


\section{Theoretical framework}

The game theory is adopted to analyse competition between Arik Air and Aero Contractors. One frequently cited example of descriptive use of game theory is the prisoner's dilemma game [3,6-10]. The prisoner's dilemma game is one of the classic examples of noncooperative game in static form. In this game, there are two players and each player have one turn, and the turns are simultaneous. The essential elements of simultaneous play are that each player moves without knowing the move of the other. Each player has two possible strategies-to maintain innocence or to cravenly confess. If both players maintain innocence, they will increase their payoffs. However, if they are induced with a promise of few years in jail by confessing, then the payoffs might be reduced. The implication of prisoner's dilemma to firms in competitive industry is to maintain current strategy that gives each player maximum payoffs.

In view of this, in any game of analysis, linear programming has been found mathematically to provide optimal solution to the players (Afrousheh et al. [11]; Cong et al. [12]; Zimmermann et al. [13]; Andrews et al. [14]), historically, ideas of linear programming inspire many basic concepts of optimisation theory such as duality, decomposition and importance of convexity and its generalisations $[15,16]$. In addition, it is useful in modelling issues of planning, routing, scheduling, allocation and design. An evaluation of 500 largest firms in the world showed that $85 \%$ of them have used linear programming [11, 1720]. It is in the light of this that this current study utilised linear programming algorithm in finding the optimal strategy and the payoffs emanating from such optimal strategy for the two selected firms in the Nigerian domestic aviation sector.

\section{Empirical literature}

Early literature has made reasonable efforts to build different models that explain nature, strategies, and behaviour of firms to cope with their environment. For instance, Bell [21] once argued that a firm's managerial asset is a key driver of competition in any industry. Chen et al. [22] in their study postulated that market competition and internal governance are critical for assessing competition in Taiwan. Sanjo [23] suggested that the capital based on a firm and the business location is critical for competition. Further on competition, some studies claimed that the degree of the firm's orientation is crucial in surviving the dynamic competitiveness in the face of uncertain and highly challenging business environment [24-27].

Recent studies attributed consistent failure and poor performance of businesses across the globe to poor management and lack of organisational culture (Chen et al. [28]; Yang and Dixon [29]). Chen et al. [28] reasoned that some firms fail to contest their position in their respective industry due to poor management capacity and other organisational factors. Luo et al. [30] observed that organisational culture and the attitude of management to compete are simultaneous factors that could juxtapose the level of success or failure that a firm attains. Some scholars called attention to how long-term development and strategic management drive competition among firms [31-34]. Wang et al. [31] contend that organisations with knowledge sharing skills and manager's training capabilities are more likely to survive the pressure of competition. Dorn et al. [35] promoted the stance that the structure, strategy and policy operated by an organisation are some of the predetermined factors that keep shaping and reshaping the nature of the organisation's behaviour towards competition. Further on the debate of organisation and motivators of competition, other scholars argued for interpersonal relationship and corporate identity as major movers of firm's competition, especially in the aviation industry [36-39]. Ceptureanu et al. [40] concluded in their work that competitive performance has significant implication on the overall benefits and outcome of the organisation's performance/ sustainability.

In German, Barry and Nienhueser [41] examined the low-cost airline industry and reported that competitive pressure stemming from European aviation demand for low-cost travelling is major driver of competition in the German aviation industry.

In the USA, Velu [42] examined the level of dominance in firms and drivers of competition. He argued that the degree of innovation experienced within the system was major contending factor that determined competition in the US economy.

In the Polish economy, Klimas [43] identified the gap in competition in the Polish aviation industry and suggested that organisational culture and orientation are key drivers of competition in the industry.

In India, Singh [44] measured the competitive service quality performance of aviation firms and provided evidence that traveller's rate was a major driver of competition among firms in the Indian aviation industry. The author further stressed that the aviation industry in India has undergone rapid transformation with the liberalisation of the sector leading to increase in cost, tight profit margins, and increasing competition among airlines. Thus, an airline's success depends heavily on its ability to retain old customers and attract new ones.

In Korea, Park et al. [45] investigated whether and how service quality and corporate social responsibility (CSR) significantly affect behavioural intention of customers 
to use or not to use an airline, through customer satisfaction survey among South Korean airline service providers. They explored an integrated research model and provided evidence that economic, social, and environmental responsibilities, as well as in-flight service quality, significantly determined customers' satisfaction. Again, they concluded there were notable connections between customer satisfaction and behavioural intention to use.

Adler and Hanany [46] compared aviation markets under conditions of competition, code sharing contracts and anti-trust immune alliances, assuming that demand for flights depends on both fares and the level of frequency offered. Using a hybrid competitive/cooperative game theoretic framework, we showed that the stronger the inter-airline agreement on overlapping routes, the higher the producer surplus. We also demonstrated that under asymmetric and uncertain demand, code sharing on parallel links might be preferable to competitive outcomes for multiple consumer types.

Alderighi et al. [47] examined the price setting behaviour of full-service airlines in European passage aviation market. The authors developed a model of airline competition, which accommodates various market structures and provided evidence that competition in the aviation market in Europe was measured by price behaviour among the aviation firms.

In all the paper reviewed above, a crucial sustained assumption is that competition remains the paramount for firm to survive their business environment. However, it is unclear whether increase or decrease in competition can improve customer patronage and reassure greater output. In particular, majority of the studies seems silent on the nature and pattern of competition that can be used in the aviation industry. For instance, some studies claimed that uncertainty in demand can make it impossible for firm to compete [46]. Other studies argued that price setting behaviour are drivers of competition [47]. Thus, the lack of consensus among scholars on whether pricing behaviour or demand uncertainty are the drivers of competition motivate further re-examination of this link. One common feature among these studies, however, is the heavy reliance on the game theoretical approach. The combination of game theory and linear programming were used to aid the analysis of this present study too.

\section{Research method}

We worked with the empirical strategy of Ignatius et al. [48] and Straub and Schaefer [18] to determine the optimal strategy and the payoffs from such strategy so chosen by the two firms-Arik Air and Aero Contractors, which are the leading domestic aviation firms.
We assumed that firms select their strategies on the basis of probability. Let $p 1, p 2, \ldots, p m$ be the probabilities with which firm I will employ each of its $\mathrm{n}$ strategies, where $0 \leq p i \leq 1(i=1, \ldots, n)$ and $\sum_{i=1}^{n} p i=1$. We assumed that some random process is employed by firm I to select a particular strategy and the strategy so chosen corresponds to the selected number. A random number selected does not give firm II the opportunity to anticipate firm I's choice even if she knows firm I's probabilities. Firm II can randomise its strategy selection by assigning the probabilities $x 1, x 2, \ldots, x n$ to its strategy, where $0 \leq x i \leq 1(i=1, \ldots, n)$ and $\sum_{i=1}^{n} x i=1$.

The probabilities, which the firms selected employed, are defined as optimal if:

$$
\begin{aligned}
& \sum_{i=1}^{n} b i j x i \geq V i=1, \ldots, n \\
& \sum_{i=1}^{n} c i j x i \leq V i=1, \ldots, m
\end{aligned}
$$

where $V$ is the value of the game. Equation 1 states that firm I's expected profits is at least as great as $V$ if firm II employs any of its pure strategies with a probability of one.

A fundamental theory of game theorem states that a solution that satisfies Eqs. (1) and (2) always exists, and that $V$ is unique. If both firms select their strategies on a probabilistic basis, firm I's expected profit, E1 is determined from Eq. (1) as:

$$
\mathrm{Q} 1=\sum_{i=1}^{n} \sum_{i=1}^{n} \text { bijpixi } \geq V
$$

Firm II's expected loss, E2 is determined from Eq. (2) as:

$$
Q 2=\sum_{j=1}^{n} \sum_{i=1}^{n} \text { cijpixi } \leq V
$$

The middle term in Eqs. (3) and (4) is identical. That is firm I's expected profit equals firm II's expected loss. Combining Eqs. (3) and (4) yields $V \leq Q 1 \leq Q 2 \leq V$.

This proves that $Q 1=Q 2=V$. These relations state that the expected outcome is the same for the two firms if both employ their optimal probabilities.

By converting their games into linear programming format, optimal strategies for the two firms and the value for the game can be determined. First, we consider cases in which the value of the game is positive. That is $V>0$. From the backward induction game, we analysed the optimal strategies starting from firm II.We define the variables for firm II as: 


$$
X_{j}=\frac{x i}{V} \quad j=1, \ldots, n
$$

By definition,

$$
\frac{1}{V}=X_{1}+X_{2}+\cdots+X_{n}
$$

It is expected that firm II will make its maximum expected loss as small as possible, or equivalently, it desires to make $\frac{1}{V}$ as large as possible. The linear programming equivalent is to find values for $X_{j} \geq 0(j=1, \ldots, n)$ which maximises Eq. (6) subject to

$$
x_{i 1} X_{1}+x_{i 2} X_{2}+\cdots+x_{i n} X_{n} \leq 1 i=1, \ldots, n
$$

\section{Sources and measurement of data}

The data used to estimate this model are annual secondary data obtained from the Nigerian Civil Aviation Authority (NCAA) based on the existing records of Arik Air and Aero Contractors. Annual data on Arik Air and Aero Contractors on airfare and passengers' volume (as the measure of output) are utilised. A linear programming model is developed to determine an optimal resource strategy, and the model is used to select the best strategy between airfare and output proxied by passengers' volume and payoffs from each strategy.

The airfare used covered both the economy class and business class. We do not make distinction between the economy class and business class, as classes' fares are totalled and averaged. The passengers' volume as a measure of output is totalled from January to December of 2014. The periodicity is based on constraints in data availability and motivation discussed in the introduction. Linear Programming Solver (LPS), version 1.11.1, was used to simulate the model.

\section{Experimental results}

In this section, we present the outcome of our experimental results and discussions, which allow us to decide regarding the future prospect of these organisations.

Following the data obtained from the NCAA, we can draw tables to represent the value as follows (Table 1):

Table 2 shows the entries of the extracted dataset in the matrix form based on row and column. This permits us to

Table 1 Airfare and passengers' strength of Arik Air and Aero Contractors. Source: Researchers (2019)

\begin{tabular}{lll}
\hline Companies & \multicolumn{2}{l}{ Objectives } \\
\cline { 2 - 3 } & Average air fare & Passengers' strength \\
\hline Arik Air & $47,057.68$ & $1,987,691$ \\
Aero Contractors & $12,898.72$ & $1,833,292$ \\
\hline
\end{tabular}

\begin{tabular}{|c|c|c|}
\hline \multirow[t]{2}{*}{ Companies } & \multicolumn{2}{|l|}{ Objectives } \\
\hline & Average air fare & $\begin{array}{l}\text { Passengers } \\
\text { volume }\end{array}$ \\
\hline Arik Air & 47 & 19 \\
\hline Aero Contractors & 12 & 18 \\
\hline
\end{tabular}

Table 2 Approximated figure on air fare and passengers' volume. Source: Researchers (2019)

have a linear programming problem for Arik Air solution. Here, $X_{1}$ represent airfare and $X_{2}$ represent passengers' volume and let $V$ be the value of the game.

Arik Air solution

$$
\begin{aligned}
& \text { Max. } X_{0}=X_{1}+X_{2} \\
& \text { S.t. } \quad 47 X_{1}+19 X_{2} \leq 1 \\
& 12 X_{1}+18 X_{2} \leq 1
\end{aligned}
$$

Putting the LPP into standard form, we have

$$
\begin{aligned}
& \text { Max. } X_{0}=X_{1}+X_{2} \\
& \text { S.t. } \quad 47 X_{1}+19 X_{2}+S_{1}=1 \\
& 12 X_{1}+18 X_{2}+S_{2}=1 \\
& X_{1}, X_{2}, S_{1}, S_{2} \geq 0 .
\end{aligned}
$$

Solving using the simplex method gives

$$
X_{1}=0 ; \quad X_{2}=1 / 19 ; \quad X_{0}=1 / 19
$$

The value of the game can be obtained as $V=1 / X_{0}$. $V=1 / 1 / 19=19$. The required probability is $X_{2}=X_{2} / X_{0}=1 / 19 \times 19 / 1=1$.

Aero Contractor's solution

We can solve Aero's problem by first converting it into linear programming problem (LPP). Aero minimisation problem is dual of Arik maximisation problem, and by extension the duality theory, the conversion is as follows.

Let $y_{1}$ be the flight price and $y_{2}$ be the passengers' volume and $V$ the value of the game.

By duality theory, we have

$$
\begin{aligned}
& \text { Min. } y_{0}=y_{1}+y_{2} \\
& \text { S.t } 47 y_{1}+12 y_{2} \geq 1 \\
& 19 y_{1}+18 y_{2} \geq 1 \\
& y_{1}, y_{2}>0
\end{aligned}
$$

Apply simplex method to the dual problem to solve the minimisation problem. Introducing slack variables and rearranging the objective function, we have 


$$
\begin{aligned}
& \text { Max. } y_{0}=y_{1}+y_{2} \\
& \text { S.t } 47 y_{1}+12 y_{2}=1 \\
& 19 y_{1}+18 y_{2}=1 \\
& y_{1}, y_{2}, S_{1}, S_{2} \geq 0
\end{aligned}
$$

Putting LLP in standard form, we have

$$
\begin{aligned}
& 47 y_{1}+12 y_{2}+s_{1}=1 \\
& 19 y_{1}+18 y_{2}+s_{2}=1 \\
& y_{1}, y_{2}, S_{1}, S_{2} \geq 0
\end{aligned}
$$

By solving the LPP, the following results were obtained. Thus, $y_{1}=1 / 19, y_{2}=0, y_{0}=1 / 19$. The value of the game is obtained as $V=1 / y_{0}=19$. The required probability is obtained as $Y_{1}=y_{1} / y_{0}=1 / 19 \times 19 / 1=1$, $Y_{2}=y_{2} / y_{0}=0$.

\section{Discussion of results}

This study examined the application of game theory in analysing competition in the Nigerian aviation industry by focusing on Arik Air and Aero Contractors as the basis of analysis. The results obtained using simplex method of linear programming and duality theory showed that Arik Air should place more weight on the strength of its passenger as this gives a probability value of 1 (one), while no weight should be placed on flight price as this gives a probability value of zero. If followed, this will give an optimal benefit value of \#19 million.

The solution for Aero Contractors is obtained by duality theory. The result of the analysis showed that for optimum performance, Aero Contractors should place more weight on flight price as this gives a probability value of 1.00 and no weight be placed on passengers' volume. If followed, this will give an optimal benefit value of \#19 million.

The implication of this study is that in spite of the fact that Arik Air charged the highest fare as shown in Table 1; it yet controls the largest share of the domestic aviation industry. Thus, non-price competition would serve to retain Arik Air's largest share in industry. We can, therefore, infer that non-price competition is relevant in the aviation industry. However, the result obtained for Aero Contractors showed that price matters for the airline to determine its passengers' strength. Bertrand solution, would therefore, be appropriate for Aero Contractors as this would give a benefit value of 19 million naira. Thus, we can conclude that if both firms stick to the optimal strategy, they will both share the market.

As a departure from earlier studies, the uniqueness of our result is in its general accord with the recent competitive dynamics experienced in the Nigerian Aviation industry. Our study provided evidence that Aero Contractors and Arik Air are the preferred airlines in
Nigeria (for domestic route), and they account for $73 \%$ of total airlines' preferences. Obviously, the study favours Aero Contractors because of its affordable pricing, high safety standards, good quality services, large number of travel destinations, good records for timeliness for flight departure, and effective communication of information on gate changes. Furthermore, the affordable pricing is worth mentioning here. This is consistent with the result obtained in this study.

\section{Conclusion}

The main aim of this paper is to describe the subjective behaviour of firms in the Nigerian aviation industry. We employed a game theoretic and optimisation technique to measure the degree of competition in the industry. We considered the strategies of the players based on price charges on airfare and passengers' volume to proxy each firm's output in the aviation industry. Our experimental results indicated that competition in the Nigerian aviation industry is driven by customer patronage and price charged by airline firms. Thus, we concluded that game theory approach anchored on the linear programming has helped to describe the responses of the players and that the optimal strategy of both firms examined increased customer's patronage by manipulating airfares based on varied time factor to enable them survive the competition in the industry.

In particular, Arik Air should place more weight on retaining its passengers through other product features other than price. If followed, it will give the firm a payoff of 19 million Naira, while Aero Contractors should place more weight on airfare. If followed, this will give the firm a payoff of 19 million naira as obtained in the study's analysis. In this case, they will share the market equally.

We therefore recommend that Arik Air and Aero Contractors should use the result obtained in this research work in their resource allocation and planning. This will certainly yield encouraging benefits. Firms should engage in a healthy competition by using game theory to determine their saddle point and working constantly on that point.

Furthermore, the managerial implication of this study is numerous. First, the positioning of our analysis clearly emphasised that price setting behaviour plays a predominant role in the hallmark strategy of the aviation firm in Nigeria. The results further confirm that surviving the harsh business environment requires that aviation firms involve in various pricing practises such as price penetration, price skimming, and price discrimination. The motivation behind this pricing behaviour is connected with dynamic market condition as well as the environment where the firm operates. While management can use pricing decision to output growth through 
price adjustment mechanism, additional service delivery to ensure that customer expectation are met must be given further considerations. Finally, we advise that price behaviour can be a good strategy for competition, but care must be taken not to use excessive pricing to persuade customer as the consequences might have aftermath effects during demand shock or changes in market conditions (Additional file 1: Table S1).

\section{Supplementary information}

Supplementary information accompanies this paper at https://doi. org/10.1186/s43093-020-00019-8.

Additional file 1: Table S1. Simulations.

\section{Abbreviations}

CSR: Corporate social responsibility; NCCA: Nigerian Civil Aviation Authority; LPP: Linear programming problem; LPS: Linear programming solver; US: United States.

\section{Acknowledgements}

The authors are grateful to the Nigerian Civil Aviation Authority for providing dataset used in this study. We also thank the editors and reviewers for their constructive comments.

\section{Authors' contributions}

The authors contribute in the ratio 60-40\%. Corresponding author (OA 60\%); second author (MD 40\%). MD analysed and interpreted the preliminary analysis and provided the review of the empirical literature. OA prepared the introductory and methodological sections of the paper, and performed the full empirical analysis of the paper. Both authors read and approved the final manuscript.

\section{Funding}

Not applicable.

\section{Availability of data and materials}

This is available on request.

\section{Competing interests}

The authors declare that they have no competing interests.

\section{Author details}

${ }^{1}$ Business School, University of Aberdeen, Block C, Room F02, Edward Wright Annexe, Aberdeen AB23 3RX, UK. ${ }^{2}$ Department of Economics, University of Lagos, Lagos, Nigeria.

Received: 12 July 2019 Accepted: 26 February 2020 Published: 21 May 2020

\section{References}

1. Jimenez E, Claro J, de Sousa JP (2014) The airport business in a competitive environment. Procedia-Soc Behav Sci. 2014(111):947-954. https://doi. org/10.1016/j.sbspro.01.129

2. Oghojafor BEA, Alaneme GC (2014) Nigeria airways: the grace and grass experience (a case study). Int J Bus Soc Sci 5(13):138-150

3. Rousselière D (2019) A flexible approach to age dependence in organizational mortality: comparing the life duration for cooperative and noncooperative enterprises using a Bayesian generalized additive discrete time survival model. J Quant Econ 17:829-855. https://doi.org/10.1007/ s40953-019-00164-0

4. OECD (1999) Infrastructural development and regulatory reform in sub Saharan Africa: the case of air transport. In: OECD working paper no 154 (154)
5. ICAO (2010) Order from Chaos: answering Haiti call ad contributing to its renewal. Int Civ Aviat Organ 65(5):347

6. Pothos EM, Perry G, Corr PJ, Matthew MR, Busemeyer JR (2011) Understanding cooperation in the Prisoner's Dilemma game. Pers Individ Dif 51(3):210-215. https://doi.org/10.1016/j.paid.2010.05.002

7. Ellett L, Allen-Crooks R, Stevens A, Wildschut T, Chadwick P (2013) A paradigm for the study of paranoia in the general population: the Prisoner's Dilemma game. Cogn Emot 27(1):53-62. https://doi.org/10.1080/02699 931.2012 .689757

8. Meng X, Sun S, Li X, Wang L, Xia C, Sun J (2015) Interdependency enriches the spatial reciprocity in prisoner's dilemma game on weighted networks. Phys A Stat Mech Appl 442:388-396. https://doi.org/10.1016/j.physa .2015.08.031

9. Gao J, Li Z, Liu Y, Wang $L$ (2011) The effect of recommended role models in prisoner's dilemma game. Phys A Stat Mech Appl 390(5):811-816. https ://doi.org/10.1016/j.physa.2010.10.048

10. Zhang C, Zhang J, Xie G, Wang L (2011) Effects of encounter in a population of spatial prisoner's dilemma players. Theor Popul Biol 80(3):226-231. https://doi.org/10.1016/j.tpb.2011.06.007

11. Afrousheh K, Makdisi Y, Kokaj J, Marafi M, Mathew J, Pichler G (2013) Collision induced modification of spectral lines in the first autoionization region of barium. Eur Phys J D 67(12):262. https://doi.org/10.1140/epjd/ e2013-40542-2

12. Cong R, Wu T, Qiu YY, Wang L (2014) Time scales in evolutionary game on adaptive networks. Phys Lett Sect A Gen At Solid State Phys 378(13):950955. https://doi.org/10.1016/j.physleta.01.041

13. Zimmermann M, Schopf D, Lütteken N et al (2018) Carrot and stick: A game-theoretic approach to motivate cooperative driving through social interaction. Transp Res Part C Emerg Technol 88(February):159-175. https ://doi.org/10.1016/j.trc.01.017

14. Andrews DWK, Marmer V, Yu Z (2018) On optimal inference in the linear IV model. SSRN 10:457-485. https://doi.org/10.2139/ssrn.3132292

15. Fu K, Chen Z, Sarker BR (2019) An optimal decision policy for a singlevendor single-buyer production-inventory system with leaning effect, fuzzy demand and imperfect quality. J Inf Optim Sci 40(3):633-658. https ://doi.org/10.1080/02522667.2018.1427026

16. Houssein EH, Hamad A, Hassanien AE, Fahmy AA (2019) Epileptic detection based on whale optimization enhanced support vector machine. J Inf Optim Sci 40(3):699-723. https://doi.org/10.1080/02522 667.2018 .1453671

17. Yu H, Tseng HE, Langari R (2017) A human-like game theory-based controller for automatic lane changing. Transp Res Part C Emerg Technol. 88:140-158. https://doi.org/10.1016/j.trc.2018.01.016

18. Straub ER, Schaefer KE (2019) It takes two to tango: automated vehicles and human beings do the dance of driving - four social considerations for policy. Transp Res Part A Policy Pract 122:173-183. https://doi. org/10.1016/j.tra.2018.03.005

19. Gaynor MS, Kleiner S, Vogt W (2013) A structural approach to market definition with an application to hospital industry. J Ind Econ 61(2):243-289

20. Sumathi $P(2016)$ A new approach to solve linear programming problem with intercept values. J Inf Optim Sci 37(4):495-510. https://doi. org/10.1080/02522667.2014.996031

21. Bell GG (2005) Clusters, networks, and firm innovativeness. Strateg Manag J 26(3):287-295. https://doi.org/10.1002/smj.448

22. Chen A, Kao L, Lu CS (2014) Controlling ownership and firm performance in Taiwan: the role of external competition and internal governance. Pac Basin Finance J 29:219-238. https://doi.org/10.1016/j.pacfin.2014.04.007

23. Sanjo Y (2014) The role of firm ownership in policy competition for foreign direct investment between asymmetric countries. Int Rev Econ Finance 35:110-121. https://doi.org/10.1016/j.iref.09.009

24. Chin CH, Lo MC, Ramayah T (2014) Market orientation and organizational performance: the moderating role of service quality. SAGE Open 3(4):2158244013512664. https://doi.org/10.1177/2158244013512664

25. Jönsson C (1981) Sphere of flying: the politics of international aviation. Int Organ 35(02):273. https://doi.org/10.1017/s0020818300032446

26. Horstmann N, Krämer J, Schnurr D (2018) Number effects and tacit colIusion in experimental oligopolies. J Ind Econ 66(3):650-700. https://doi. org/10.1111/joie.12181

27. Eceral TÖ, Köroğlu BA (2015) Incentive mechanisms in industrial development: an evaluation through defense and aviation industry of Ankara. 
Procedia-Soc Behav Sci 195:1563-1572. https://doi.org/10.1016/j.sbspr 0.2015 .06 .192

28. Chen MC, Cheng SJ, Hwang Y (2005) An empirical investigation of the relationship between intellectual capital and firms' market value and financial performance. J Intellect Cap 6(2):159-176. https://doi. org/10.1108/14691930510592771

29. Yang M, Dixon RK (2012) Investing in efficient industrial boiler systems in China and Vietnam. Energy Policy 40:432-437. https://doi.org/10.1016/j. enpol.2011.10.030

30. Luo X, Slotegraaf RJ, Pan X (2006) Simultaneous role of cooperation. J Mark 70(April):67-80. https://doi.org/10.1509/jmkg.70.2.067

31. Wang H, He J, Mahoney JT (2008) Top management incentive compensation and knowledge sharing in multinational corporations. Strateg Manag J 37(1):116-132. https://doi.org/10.1002/smj.712

32. Bengtsson M, Kock S, Lundgren-Henriksson EL, Näsholm MH (2016) Coopetition research in theory and practice: growing new theoretical, empirical, and methodological domains. Ind Mark Manag 57:4-11. https ://doi.org/10.1016/j.indmarman.05.002

33. Squazzoni F, Jager W, Edmonds B (2014) Social simulation in the social sciences: a brief overview. Soc Sci Comput Rev 32(3):279-294. https://doi. org/10.1177/0894439313512975

34. Squazzoni $F$ (2014) The agent-based modeling approach through some foundational monographs. Princ Appl Soc Phenom 55(4):827-840

35. Dorn S, Schweiger B, Albers S (2016) Levels, phases and themes of coopetition: a systematic literature review and research agenda. Eur Manag J 34(5):484-500. https://doi.org/10.1016/j.emj.02.009

36. Kim Y (1990) Prospects for Japanese-US trade and industrial competition. Asian Surv 30(5):493-504

37. Hahn JH, Kim SH (2016) Interfirm bundled discounts as a collusive device. J Ind Econ 64(2):255-276. https://doi.org/10.1111/joie.12097

38. Noel MD (2018) Gasoline price dispersion and consumer search: evidence from a natural experiment. J Ind Econ 66(3):701-738. https://doi. org/10.1111/joie. 12179

39. Hu W, Xiao J, Zhou X (2014) Collusion or competition? Interfirm relationships in the chinese auto. J Ind Econ 62(1):1-41

40. Ceptureanu SI, Ceptureanu EG, Olaru M, Vlad LB (2018) An exploratory study on coopetitive behavior in oil and gas distribution. Energies 11(5):1-19. https://doi.org/10.3390/en11051234
41. Barry M, Nienhueser W (2010) Coordinated market economy/liberal employment relations: low cost competition in the german aviation industry. Int J Hum Resour Manag 21(2):214-229. https://doi. org/10.1080/09585190903509522

42. Velu C (2016) Evolutionary or revolutionary business model innovation through coopetition? the role of dominance in network markets. Ind Mark Manag 53:124-135. https://doi.org/10.1016/j.indma rman.2015.11.007

43. Klimas P (2016) Organizational culture and coopetition: an exploratory study of the features, models and role in the Polish Aviation Industry. Ind Mark Manag 53:91-102. https://doi.org/10.1016/j.indmarman.2015.11.012

44. Singh AK (2016) Competitive service quality benchmarking in airline industry using AHP. Benchmarking 23(4):768-791. https://doi. org/10.1108/BIJ-05-2013-0061

45. Park E, Lee S, Kwon SJ, del Pobil AP (2015) Determinants of behavioral intention to use South Korean airline services: effects of service quality and corporate social responsibility. Sustainability 7(9):12106-12121. https ://doi.org/10.3390/su70912106

46. Adler N, Hanany E (2015) Regulating inter-firm agreements: the case of airline codesharing in parallel networks. Transp Res Part B Methodol 84:31-54. https://doi.org/10.1016/j.trb.12.002

47. Alderighi M, Cento A, Nijkamp P (2012) Rietveld P (2012) Competition in the European aviation market: the entry of low-cost airlines. J Transp Geogr 24:223-233. https://doi.org/10.1016/j.jtrangeo.008

48. Ignatius J, Tan TS, Dhamotharan L, Goh M (2018) Deregulation control by mergers and acquisitions: a game theoretic analysis of the Chinese Airline Industry. Technol Econ Dev Econ 24(6):2277-2294. https://doi. org/10.3846/20294913.2016.1266410

\section{Publisher's Note}

Springer Nature remains neutral with regard to jurisdictional claims in published maps and institutional affiliations.

\section{Submit your manuscript to a SpringerOpen ${ }^{\circ}$ journal and benefit from:}

- Convenient online submission

- Rigorous peer review

- Open access: articles freely available online

- High visibility within the field

- Retaining the copyright to your article

Submit your next manuscript at $\boldsymbol{\nabla}$ springeropen.com 